3 Bisno AL. Hyposplenism and overwhelming pneumococcal infection: a reappraisal. Am J Med Sci 1971;262:101-7

4 Gilbert B, Menetray C, Belin V, Brosset P, de Lumley L, Fisher A. Familial isolated congenital asplenia: a rare, frequently hereditary dominant condition, often detected too late as a cause of overwhelming pneumococcal sepsis. Report of a new case and review of 31 others. Eur J Pediatr 2002;161:368-72

5 Kaplan SL, Mason EO, Wald ER, et al. Six year multicentre surveillance of invasive pneumococcal infections in children. Pediatr Inf $J$ 2002;21:141-7

\section{Pseudophaeochromocytoma in two young Africans}

\author{
O E Okosieme MRCP R E Morse FRCP
}

J R Soc Med 2004;97:583-584

Patients with essential hypertension may present with a clinical syndrome mimicking phaeochromocytoma.

\section{CASE HISTORIES}

\section{Case 1}

An African man aged 36 was seen as an emergency with dysphasia, left facial weakness and a left hemiparesis. Hypertension had been detected by his general practitioner six months earlier and treated with bendroflumethiazide, but blood pressure control had been erratic, with frequent episodes of headache, palpitations and sweating. On admission he had a blood pressure of 240/120 $\mathrm{mmHg}$, bounding tachycardia and a heaving displaced apex. Proteinuria was $2+$ but there was no papilloedema. The chest radiograph, electrocardiogram and echocardiogram indicated left ventricular hypertrophy. CT of the brain revealed infarcts in the right caudate and thalamic nuclei.

Labetalol was prescribed for the hypertension but the blood pressure fluctuated widely, reaching peaks of $250 / 150 \mathrm{mmHg}$. A suspicion of phaeochromocytoma was supported by raised 24-hour urinary excretion of noradrenaline, metadrenaline, and hydroxymethoxymandelic acid (HMMA) (Table 1). However, when labetalol was stopped, the results of repeat tests were normal. Plasma renin activity (PRA) was $3.60 \mathrm{pmol} / \mathrm{L}$ (reference range $1.1-2.7)$ and aldosterone $120 \mathrm{pmol} / \mathrm{mL} / \mathrm{h} \quad(100-450)$. Abdominal CT was normal and on further investigations

Department of Medicine, University Hospital of Wales, Cardiff CF14 4XN, Wales UK

Correspondence to: Dr O E Okosieme

E-mail: okosiemeoe@cf.ac.uk no secondary cause of hypertension could be found. Subsequently, blood pressure control was achieved with an angiotensin-converting enzyme inhibitor and an alphablocker and he made a gradual neurological recovery.

\section{Case 2}

An African man of 30 was referred by his general practitioner for investigation of episodic dizziness, headaches, palpitations, sweating and tremors. Symptoms occurred in stereotypic fashion several times a day, sometimes lasting up to an hour and leaving him exhausted. There were no obvious precipitating stresses. A borderline raised blood pressure had been documented on several past surgery visits. Two of his sisters had hypertension. There was no proteinuria or papilloedema. The electrocardiogram was consistent with left ventricular hypertrophy but other investigations, including CT of the brain, yielded nothing of note.

He was admitted for exclusion of phaeochromocytoma. Inpatient monitoring revealed a pattern of symptomatic hypertensive episodes with blood pressure peaks of 200/ $140 \mathrm{mmHg}$. 24-hour urinary catecholamines on two separate days were normal (Table 1). PRA was within normal limits at $1.20 \mathrm{pmol} / \mathrm{L}$, as was aldosterone at $310 \mathrm{pmol} / \mathrm{mL} / \mathrm{h}$. Other secondary causes of hypertension were excluded and his symptoms and blood pressure control improved on verapamil and atenolol.

\section{COMMENT}

Phaeochromocytoma should be considered in the evaluation of patients with symptomatic hypertensive episodes because it is potentially fatal if unrecognized. Confident exclusion of this condition can prove challenging. The diagnosis rests on demonstration of supranormal amounts of catecholamines or metabolites in urine or plasma. However, most of the widely used tests are prone to both false-negative and falsepositive results. The most reliable biochemical screens for phaeochromocytoma are 24-hour urine estimations of catecholamines, metanephrines and vanillylmandelic acid (VMA) as well as plasma catecholamines and metanephrines. ${ }^{1}$ Of these, VMA has the lowest sensitivity (64\%) but its specificity is high (95\%); 24-hour urinary catecholamines have better sensitivity (86\%). The plasma metanephrines (sensitivity 99\%, specificity 89\%) have been advocated as the test of first choice but are not widely available. ${ }^{1}$

In both our patients, phaeochromocytoma was excluded by the finding of normal urinary catecholamines. However, hypertensive patients with equivocal biochemical screens require further testing and the pentolinium suppression test is the preferred pharmacodynamic test. Pentolinium suppresses sympathetic overactivity in patients with 


\begin{tabular}{|c|c|c|c|c|c|}
\hline Day & $\begin{array}{l}\text { Noradrenaline } \\
\text { (reference range } \\
60-660 \mathrm{nmol} / 24 \mathrm{~h} \text { ) }\end{array}$ & $\begin{array}{l}\text { Adrenaline } \\
\text { (reference range } \\
15-160 \mathrm{nmol} / 24 \mathrm{~h} \text { ) }\end{array}$ & $\begin{array}{l}\text { Dopamine } \\
\text { (reference range } \\
540-4440 \mathrm{nmol} / 24 \mathrm{~h} \text { ) }\end{array}$ & $\begin{array}{l}\text { HMMA } \\
\text { (reference range } \\
<35 \mu \mathrm{mol} / 24 \mathrm{~h} \text { ) }\end{array}$ & $\begin{array}{l}\text { Metadrenaline } \\
\text { (reference range } \\
<6.5 \mu \mathrm{mol} / 24 \mathrm{~h} \text { ) }\end{array}$ \\
\hline \multicolumn{6}{|c|}{ Case 1} \\
\hline 3 & 746 & 86 & 1747 & 39 & 9.7 \\
\hline 6 & 243 & 52 & 1756 & 26 & 5 \\
\hline 10 & 180 & 37 & 1195 & 7 & - \\
\hline 14 & 150 & 26 & 1610 & 14 & - \\
\hline \multicolumn{6}{|c|}{ Case 2} \\
\hline 4 & 125 & 36 & 883 & 14 & - \\
\hline 8 & 52 & 17 & 684 & 11 & - \\
\hline
\end{tabular}

HMMA=hydroxymethoxymandelic acid. Urinary catecholamines were measured by high performance liquid chromatography with electrochemical detection, urinary HMMA by gas chromatography and urinary metadrenaline by the Pisano spectrophotometric method

primary hypertension, and a normal result effectively excludes a phaeochromocytoma. ${ }^{2}$ An abnormal result is an indication for diagnostic localization with MRI, CT or a metaiodobenzylguanidine (MIBG) scan. MIBG scanning is not sensitive enough to exclude phaeochromocytoma (sensitivity 77-90\%) but is useful in instances where CT or MRI have failed to localize a biochemically proven tumour. ${ }^{3}$

Certain clinical situations may further blur the distinction between essential hypertension and phaeochromocytoma. In the first patient a suspicion of phaeochromocytoma was enhanced by the finding of raised urinary catecholamines and metabolites but the patient was then taking labetalol, a known cause of false-positive results. ${ }^{4}$ Subsequent tests on stopping the medication were normal. In addition, this patient had a cerebral infarction, which itself can result in transient catecholamine increases. ${ }^{5}$ An unusual finding in this patient was the high renin activity. Though suggestive of the generalized sympathoadrenal activation common to both phaeochromocytoma and subsets of primary hypertension, this was not accompanied by a raised aldosterone. The reason for this is unclear but such renin/aldosterone dissociation has been described in critically ill patients. ${ }^{6}$ Conversely, renin activity in the second patient was low-borderline, with aldosterone in the upper range of normal. Low renin is not uncommon in black persons with primary hypertension; moreover, a recent study found a risk of primary hypertension in people with aldosterone levels in the upper-normal range. ${ }^{7}$
With the exclusion of secondary causes of hypertension both patients therefore have essential or primary hypertension. Primary hypertension as a phaeochromocytoma imitator is well-recognized but seldom reported. ${ }^{8}$ Both our patients were young black males, a group in whom pseudophaeochromocytoma has not been emphasized and who are particularly vulnerable to end-organ damage from hypertension. ${ }^{9}$

\section{REFERENCES}

1 Lenders JW, Pacak K, Walther MM, et al. Biochemical diagnosis of pheochromocytoma: which test is best? JAMA 2002;287:1427-34

2 Brown MJ, Allison DJ, Jenner DA, Lewis PJ, Dollery CT. Increased sensitivity and accuracy of phaeochromocytoma diagnosis achieved by use of plasma-adrenaline estimations and a pentolinium-suppression test. Lancet 1981;1:174-7

3 Ilias I, Pacak K. Current approaches and recommended algorithms for the diagnostic localization of pheochromocytoma. J Clin Endocrinol Metab 2004;89:479-91

4 Bouloux PM, Featherstone RM, Clement-Jones V, Rees LH, Goligher JE. Erroneous diagnosis of phaeochromocytoma in hypertensive patient on labetalol. J R Soc Med 1985;78:588-9

5 Mazey RM, Kotchen TA, Ernst CB. A syndrome resembling pheochromocytoma following a stroke. JAMA 1974;230:575-7

6 Zipser RD, Davenport MW, Martin KL, et al. Hyperreninemic hypoaldosteronism in the critically ill: a new entity. J Clin Endocrinol Metab 1981;53:867-73

7 Vasan RS, Evans JC, Larson MG, et al. Serum aldosterone and the incidence of hypertension in nonhypertensive persons. $N$ Engl J Med 2004;351:33-41

8 Kuchel O. Pseudopheochromocytoma. Hypertension 1985;7:151-8

9 Post WS, Hill MN, Dennison CR, Weiss JL, Gerstenblith G, Blumenthal RS. High prevalence of target organ damage in young, African American inner-city men with hypertension. J Clin Hypertens (Greenwich) 2003;5:24-30 